\title{
Pollution as a source of endogenous fluctuations and periodic welfare inequality in OLG economies
}

\author{
Thomas Seegmuller* and Alban Verchere ${ }^{\ddagger}$
}

June 18, 2002

\begin{abstract}
This article examines the conditions under which endogenous fluctuations and periodic welfare inequality can emerge in OLG economies having an environmental dimension.

Résumé : cet article examine les conditions sous lesquelles des fluctuations endogènes et une inéquité périodique du bien-être peuvent émerger dans des économies à GI prenant en compte une dimension environnementale.
\end{abstract}

Keywords: Endogenous fluctuations; Environmental quality; Intergenerational equity

JEL classification: E32, Q20

\section{Introduction}

Since Howarth and Norgaard (1992) one knows that in OLG economies, the risk that present generations sacrifice the welfare of future ones is high, given that the former are engaged in polluting activities which effects go on for a long time after their death. Moreover as it was shown the integration of an efficient tax scheme and intergenerational transfers would not guarantee a sustained development for future generations because of the recurring problem of the social discount rate.

Within a framework very close to that of John and Pecchenino (1994), we show that another type of intergenerational inequity can appear, however

*BETA-Theme, Louis Pasteur University, 61, avenue de la Forêt-Noire 67085 Strasbourg Cedex France, Tel: (33)-3-90-24-20-98, Fax: (33)-3-90-24-20-71, e-mail: seegmu@cournot.u-strasbg.fr.

${ }^{\dagger}$ Corresponding author: BETA-Theme, Louis Pasteur University, 61, avenue de la Forêt-Noire 67085 Strasbourg Cedex France, Tel: (33)-3-90-24-20-98, Fax: (33)-3-90-2420-71, e-mail: verchere@cournot.u-strasbg.fr.

${ }^{\ddagger}$ We want to thank Isabelle Maret and Théophile Azomahou for helpful comments. All remaining errors are own. 
it is not possible to hold present generations responsible for it. Indeed, in John and Pecchenino (1994) it is shown that different dynamics of capital accumulation and environmental preservation can emerge when generations contribute to an environmental maintenance sector, and considering increasing external returns or not. In the latter case, they highlight that there exists a path of monotonous convergence up to the steady state depending on the initial conditions and the length of which one observes, either a continuous growth of capital and environmental quality or conversely a fall of them up to the steady state. If dynamics would emphasize two non autarkic steady states - one stable, one unstable - then according to the initial conditions there also exists a monotonous convergence either to the autarkic equilibrium or to the higher steady state. Within a framework very close to this one, we demonstrate that endogenous fluctuations can emerge and that a new form of intergenerational inequity, qualified as cyclic or periodic, can appear.

The article is organized as follows. In section 2 we present the model and the equilibrium conditions whereas in section 3 we study the local dynamics. Section 4 establishes the welfare analysis and concludes the paper.

\section{The model}

We consider a perfectly competitive overlapping generations economy with discrete time $t=0,1, \ldots, \infty$ and perfect foresight. At each date a generation of consumers appears and lives two periods. The population of each generation is constant and normalized to one. When young, each consumer supplies one unit of labor inelastically and shares his income, $w_{t}$, between the purchase of productive capital $k_{t+1}$ and the abatement of pollution emissions $d_{t}$. When old, he rents his capital to firms, which is remunerated at the real interest factor $r_{t+1},{ }^{1}$ and consumes the final good. We further consider that consumers derive utility only at the second period of their life, from consumption $C_{t+1}$ and environmental quality. More precisely we assume that this latter decreases with the pollution stock $S p_{t+1}$ which is determined at end of period $t$ as follows:

$$
S p_{t+1}=(1-m) S p_{t}+a k_{t}-b d_{t}
$$

where $m \in(0,1)$ is the natural rate of pollution absorption, $a>0$ the emission rate of pollution by unit of capital and $b>0$ the coefficient of the linear abatement technology. Finally, $S p_{t}$ is the stock of pollution inherited from the previous period.

Each consumer maximizes his utility under his two budget constraints and the equation of pollution stock accumulation (1). The program is:

\footnotetext{
${ }^{1}$ We assume that capital totally depreciates after one period.
} 


$$
\begin{gathered}
\max C_{t+1}-\frac{S p_{t+1}^{2}}{2 B} \\
\text { s.t. }\left\{\begin{array}{l}
k_{t+1}+d_{t}=w_{t} \\
C_{t+1}=r_{t+1} k_{t+1} \\
S p_{t+1}=(1-m) S p_{t}+a k_{t}-b d_{t}
\end{array}\right.
\end{gathered}
$$

where $B>0$ is a scaling parameter.

We deduce the following first order condition:

$$
r_{t+1}=\frac{b}{B} S p_{t+1}
$$

We assume that the final good is produced by a representative competitive firm with a constant returns to scale technology $y_{t}=f\left(k_{t}\right) l_{t}$, where $f\left(k_{t}\right)$ is the intensive production function and $l_{t}$ the labor. We further assume that $f\left(k_{t}\right)$ is a continuous function and has continuous derivatives of all required orders for $k_{t}>0$, with $f^{\prime}\left(k_{t}\right)>0, f^{\prime \prime}\left(k_{t}\right)<0$ and $f(1)=1$. Firm maximizes its profits and we obtain the two usual following conditions:

$$
r_{t}=f^{\prime}\left(k_{t}\right) \equiv r\left(k_{t}\right) \text { and } w_{t}=f\left(k_{t}\right)-k_{t} f^{\prime}\left(k_{t}\right) \equiv w\left(k_{t}\right)
$$

Before determining the intertemporal equilibrium, it is useful to define the following relationships. First, we note the capital share of income $s(k)=f^{\prime}(k) k / f(k) \in(0,1)$. Moreover we define the elasticities of wage and interest rate with respect to $k: \varepsilon_{w}(k)=w^{\prime}(k) k / w(k)$ and $\varepsilon_{r}(k)=r^{\prime}(k) k / r(k)$. Finally, the elasticity of capital-labor substitution $\sigma(k)$ is determined by:

$$
\frac{1}{\sigma(k)}=\frac{d \ln (w(k) / r(k))}{d \ln k}=\varepsilon_{w}(k)-\varepsilon_{r}(k)
$$

From $f(k)=k r(k)+w(k)$, we deduce that $w^{\prime}(k)=-k r^{\prime}(k)$, and using this last relation, we finally obtain:

$$
\varepsilon_{w}(k)=\frac{s(k)}{\sigma(k)} \text { and } \varepsilon_{r}(k)=-\frac{1-s(k)}{\sigma(k)}
$$

We can now determine the intertemporal equilibrium. Substituting the first budget constraint and relation (3) into equation (1) and using (4), we have $^{2}$ :

$$
\frac{B}{b} f^{\prime}\left(k_{t+1}\right)-b k_{t+1}=(1-m) \frac{B}{b} f^{\prime}\left(k_{t}\right)+a k_{t}-b\left[f\left(k_{t}\right)-k_{t} f^{\prime}\left(k_{t}\right)\right]
$$

This equation is satisfied at each period and entirely rules the dynamic.

\footnotetext{
${ }^{2}$ We notice that labor market clears with $l_{t}=1$ since the labor supply is inelastic and equal to 1 .
} 


\section{Local dynamics}

As we study local dynamics we first analyze the existence of a steady state. From (7), we deduce that a steady state is a solution of the following equation:

$$
\frac{B}{b} m f^{\prime}(k)=(a+b) k-b\left[f(k)-k f^{\prime}(k)\right]
$$

Existence can be established by appropriately selecting the scaling parameter $B$ so as to get a normalized steady state $k=1$. Indeed, there is a unique solution $B^{*}$ to $(8)$ such that $k=1$ :

$$
B^{*}=\frac{a+b s}{s} \frac{b}{m}
$$

where $s=f^{\prime}(1)$ is the capital share of income evaluated at the steady state $k=1$.

In order to study local dynamics we differentiate equation (7) around the steady state $k=1$ :

$$
\frac{d k_{t+1}}{d k_{t}}=\frac{(1-m)(a+b s) \frac{1-s}{\sigma}+m\left(b s \frac{1-s}{\sigma}-a\right)}{(a+b s) \frac{1-s}{\sigma}+b m}
$$

In this model local endogenous fluctuations can only emerge through the occurrence of a flip bifurcation, i.e. if $\frac{d k_{t+1}}{d k_{t}} \leq-1$. This last condition is equivalent to:

$$
b(2 s(1-s)+m \sigma) \leq a((m-2)(1-s)+m \sigma)
$$

This relation is satisfied only if $\sigma>\frac{2-m}{m}(1-s)$. Under this condition, inequality (11) can be rewritten:

$$
\frac{a}{b} \geq \frac{m \sigma+2 s(1-s)}{m \sigma-(2-m)(1-s)} \equiv\left(\frac{a}{b}\right)_{F}
$$

Proposition 1 If $\sigma>\frac{2-m}{m}(1-s)$, then a cycle of period two emerge through the occurrence of a flip bifurcation when $\frac{a}{b}=\left(\frac{a}{b}\right)_{F}$.

This proposition shows that endogenous cycles can occur if the emission rate of pollution $a$ is sufficiently high regarding the coefficient of abatement technology, $b .^{3}$ The emergence of such fluctuations can be explained as follows: if the capital increases from its steady state value, the net pollution emissions as well as the next period stock of pollution increase. From the first order condition of the consumer program, it requires an higher expected interest factor. Consequently, the next period capital stock will decrease which

\footnotetext{
${ }^{3}$ The emergence of endogenous fluctuations also requires that capital and labor are not weak substitutes.
} 
is the source of endogenous cycles in this economy. Moreover, remark that $\left(\frac{a}{b}\right)_{F}$ decreases with the natural rate of pollution absorption $m$. This means that a greater natural rate of pollution absorption promotes the appearance of a cycle of period two, by facilitating the occurrence of a flip bifurcation. It is an interesting fact insofar that the greater the natural factor of assimilation is, the more the risk to observe endogenous fluctuations of activity is high. Indeed, when $m$ is high, the pollution stock mainly depends on the new net pollution emissions which reinforce the opposite effects described above.

\section{Welfare analysis}

Contrary to the case where the economy is at the steady state, all generations do not have the same level of welfare along the cycle. We can further establish that some generations have a greater utility than some others, revealing a new kind of intergenerational inequity that we could qualify as "cyclic" or "periodic".

Proposition 2 Assume that it exists a cycle of period two. It is described by two values $k_{0}$ and $k_{1}$ such that $k_{1}>1>k_{0}>0$. If $\sigma\left(k_{t}\right)>1-s\left(k_{t}\right)$ for all $t$, then $U_{1}>U_{0}$, where $U_{i}$ corresponds to the utility of a generation born when $k_{t}=k_{j}$ with $i, j=\{0,1\}$ and $i \neq j$.

Proof. Using equations (2), (3) and (4), the utility of the generation who arises at period $t$ can be rewritten:

$$
U_{t}=C_{t+1}-\frac{S p_{t+1}^{2}}{2 B}=f^{\prime}\left(k_{t+1}\right) k_{t+1}-\frac{B}{2 b^{2}} f^{\prime}\left(k_{t+1}\right)^{2} \equiv V\left(k_{t+1}\right)
$$

Hence, we have:

$$
\begin{aligned}
V^{\prime}\left(k_{t+1}\right) & =f^{\prime}\left(k_{t+1}\right)\left(1-\frac{1-s\left(k_{t+1}\right)}{\sigma\left(k_{t+1}\right)}\right)-\frac{B}{b^{2}} f^{\prime \prime}\left(k_{t+1}\right) f^{\prime}\left(k_{t+1}\right) \\
& >0, \text { because } \sigma\left(k_{t}\right)>1-s\left(k_{t}\right) \text { for all } t \text { by assumption }
\end{aligned}
$$

This last inequality means that utility increases with next period capital stock and this concludes the proof.

So, all along the cycles generations with weak utility periodically alternate with generations with a greater one. This is the main result of our quite simple model. It puts in evidence that OLG economies with environmental dimension could endogenously encounter a cyclical intergenerational inequity with loser and winner generations. The former encounter both low capital and high pollution stocks ${ }^{4}$ whereas the latter enjoy the preferable opposite

\footnotetext{
${ }^{4}$ Observe with (3) and (4) that $S p_{t+1}=\frac{B}{b} f^{\prime}\left(k_{t+1}\right)$, and so $S p_{1}<S p_{0}$ since $k_{1}>k_{0}$.
} 
situation with a higher level of welfare. As we noticed in introduction, even if it is an intergenerational inequity, one can not allot the responsibility for it to any generation in particular. Nevertheless, such a characteristic added to the risk that such a situation occurs, with then a periodic but permanent inequality of welfare between some generations and some others, will have to be seen by public authorities as an incentive to implement the means so that it actually never appears.

\section{References}

Howarth, R., and R. NorgaARd (1992): "Environmental Valuation under Sustainable Development," AEA Papers and Proceedings, American Economic Review, 82(2), 473-477.

John, A., and R. Pecchenino (1994): "An Overlapping Generation Model of Growth and the Environment," The Economic Journal, 104, 1393-1410. 